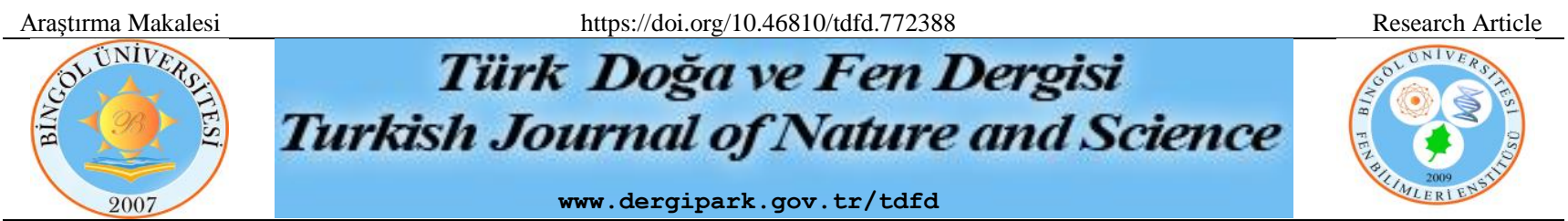

\title{
Solhan (Bingöl) Florasının Arıcılık Açısından Değerlendirilmesi
}

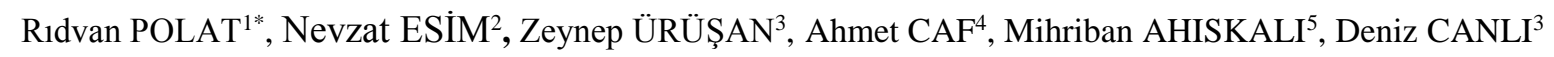

${ }^{1}$ Bingöl Üniversitesi, Ziraat Fakültesi, Peyzaj Mimarlığı Bölümü, Bingöl, Türkiye

${ }^{2}$ Bingöl Üniversitesi, Fen edebiyat Fakültesi, Moleküler Biyoloji ve Genetik Bölümü, Bingöl, Türkiye

${ }^{3}$ Bingöl Üniversitesi, Pilot Üniversite Koordinasyon Merkezi, Bingöl, Türkiye

${ }^{4}$ Bingöl Üniversitesi, Teknik bilimler Meslek yüksekokulu, Park ve Bahçe Bitkileri Bölümü, Bingöl, Türkiye

${ }^{5}$ Bingöl Üniversitesi, Gıda, Tarım ve Hayvancılık Meslek Yüksekokulu, Bitkisel ve Hayvansal Üretim Bölümü, Bingöl, Türkiye

Ridvan POLAT ORCID No: 0000-0003-0261-3671

Nevzat ESIM ORCID No: 0000-0001-5121-092X

Zeynep ÜRÜŞAN ORCID No: 0000-0002-7749-5553

Ahmet CAF ORCID No: 0000-0002-4295-7703

Mihriban AHISKALI ORCID No: 0000-0003-0580-7594

Deniz CANLI ORCID No: 0000-0001-9794-8911

*Sorumlu yazar: rpolat@bingol.edu.tr

(Alınış: 18.08.2020, Kabul: 13.10.2020, Online Yayınlanma: 23.10.2020)

Anahtar
Kelimeler
Arıcılık,
Flora,
Polen atlas,
Solhan,
Bingöl.

Anahtar

Kelimeler

Polen atlas,

Bingöl.
Öz: Bingöl ili ülkemizin önemli arıcılık merkezlerinden biridir. Bu çalışmada; Solhan (Bingöl) yöresinde gerçekleştirilen arazi çalışmaları kapsamında arı konaklama alanları ve çevre alanlarda çok sayıda arazi gezisi düzenlenmiştir. Bu kapsamda arazide yapılan yoğun gözlemler ve bölgede arıcılık yapan kişilerle uygulanan anketler 1şı̆̆ında arıların nektar, polen ve diğer arı ürünleri için kaynak olarak kullandığı bitkiler kayıt altına alınmıştır. Araştırmalar sonucunda Solhan yöresinde arıcılık açısından önemli potansiyele sahip 25 bitki familyasına ait 100 bitki taksonu tespit edilmiştir. Bu taksonlardan 7'si endemiktir. En fazla taksona sahip familyalar; Asteraceae (31), Lamiaceae (15), Fabaceae (15), Rosaceae (4), Caprifoliaceae (3), Caryophyllaceae (3), Hypericaceae (3), Asparagaceae (2) şeklindedir. Ayrıca çalışmalar kapsamında arı bitkileri üzerine yapılan palinolojik değerlendirmelerle önemli bazı taksonların polen atlası hazırlanmıştır.

\section{An Evaluation on Solhan (Bingöl/Turkey) Flora with Regard to Beekeeping}

\section{Keywords}

Beekeeping,

Flora,

Pollen atlas,

Solhan,

Bingöl.

\begin{abstract}
Bingol is one of the important beekeeping centres of our country. In this study; within the scope of field studies in Solhan (Bingol) region, many field trips were organized in apiaries and surrounding areas. In this context, the plants used by the bees as a source for nectar, pollen and other bee products were recorded by taking into consideration the intense observations in the field and the surveys conducted with the beekeepers in the region. As a result of the researches, 100 plant taxa belonging to 25 plant families with significant potential in terms of beekeeping were identified in Solhan region and 7 of these taxa are endemic. Families with the most taxa; Asteraceae (31), Lamiaceae (19), Fabaceae (15), Rosaceae (4), Caprifoliaceae (3), Caryophyllaceae (3), Hypericaceae (3), Asparagaceae (2). In addition, pollen atlas of some important local bee plants was prepared with palynological evaluations on bee plants.
\end{abstract}

\section{GİRİş}

Türkiye $814.578 \mathrm{~km}^{2}$, lik yüz ölçümünde farklı coğrafik, topografik özellikler, karasal, akdeniz, okyanus iklim kuşaklarının etkisi altında bulunması ve özelliklede üç fitocoğrafik bölgenin kesişme noktasında yer alması nedeniyle oldukça zengin bitki çeşitliliğine sahip bir ülkedir. Bu farklılıklar özel habitatların ve alt iklim bölgelerinin oluşmasını sağlayarak farklı yaşam alanları oluşturmuş ve Anadolu'da sadece flora çeşitliliğini değil 
ayrıca zengin fauna çeşitliliğini de meydana getirmiştir [1].

Türkiye florası 3649'u yani yaklaşık olarak \% 31,82' si endemik olan 11707 taksona sahiptir. Her on günde bir yeni bir bitkinin keşfedildiği ülkemiz flora zenginliği açısından önemli bir coğrafyada yer almaktadır [2]. Ülkemiz florası doğal yayılış gösteren ve arıcılık yönünden önem arz eden pek çok bitki türüne ev sahipliği yapmaktadır. Dünyada mevcut olan ballı bitki çeşit ve türlerinin \%75'ini bünyesinde barındırdı̆̆ 1 düşünülen ülkemiz dünyada arıcılık bakımından söz sahibi olan ülkeler arasında yer almaktadır [3].

Arılar polen ve nektar kaynağı olarak çiçekli bitkileri ziyaret etmektedir. Arılar beslenmelerinde protein kaynağ1 olarak polenden faydalanırken, bal üretimi için çiçek nektarlarından faydalanmaktadır. Arıcılıkta yüksek verim ve kaliteli ürün elde etmek birçok faktöre bağlıdır. Güçlü bir arı kolonisi ve arı bitkileri açısından zengin bir flora verimi etkileyen faktörlerin başında gelmektedir. $\mathrm{Bu}$ nedenle bitkisel kaynaklardan en etkin şekilde yararlanmayı sağlayacak bölgelerin tespit edilmesi ve floral kapasitelerinin belirlenmesi arı ürünlerinin üretiminde verimi ve kaliteyi olumlu yönde etkileyecektir [4].

TÜİK'in, 2019 y1lı verilerine göre ülkemizde toplamda 7929368 yeni kovan bulunmakta ve 109330 ton bal üretilmektedir. Bingöl ili istatistiklerine bakıldığında ise ilde toplamda 131790 kovan bulunurken1531,16 ton bal üretimi gerçekleştirilmektedir [5].

Bingöl, Doğu Anadolu Bölgesi Yukarı Fırat bölümünde konumlanmakta olup İran-Turan fitocoğrafik bölgesi içinde yer almaktadır. Floral zenginliği, iklimi ve yükselti farklılıkları ile arıcılık açısından yüksek potansiyele sahiptir [5]. Çalışma sahamızı oluşturan Solhan ilçesi ilin doğusunda yer almakta olup $1395 \mathrm{~m}$ yüksekliğe sahiptir. Alanda bulunan en önemli dağlar Şerafettin dağlarıdır. Esentepe (2388 m) ve Şahin (2675 m) tepesi en yüksek noktalarını oluşturmaktadır. Çevkani, Kuçekan, Kandil, Ağması, Kabak ve Şerafettin yaylaları ise bölgenin en önemli yaylalarını oluşturmaktadır [6] (Şekil 1).

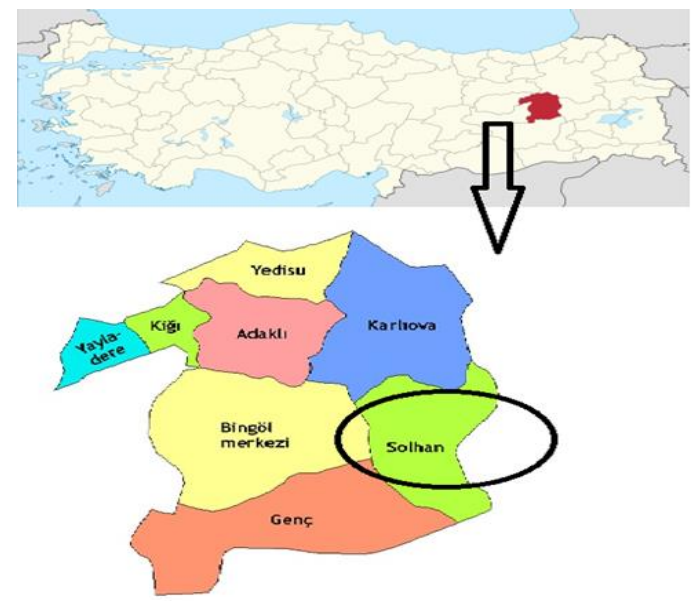

Şekil 1. Çalışma alanının genel görüntüsü
Solhan Bölgesinde arı florasının tespiti için çok sayıda arazi gezisi gerçekleştirilmiştir (Şekil 2). Arazi gezileri çerçevesinde arı konaklama alanları ve çevresinde yoğun gözlemler ve yöredeki arıcılara arı bitkileri ile ilgili anket uygulaması yapılmıştır. Araştırmalar kapsamında yörede arıların siklıkla ziyaret ettiği bitkilerin fotoğraflama ve örnek toplama işlemleri gerçekleştirilmiştir. Teşhis edilmiş bitkilerin palinolojik verileri fotoğraflanarak kayıt altına alınmıştır.

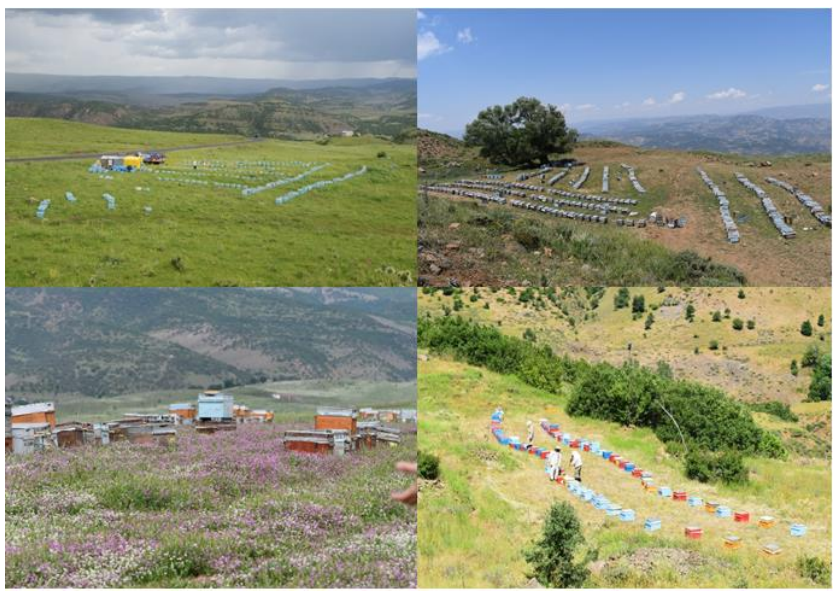

Şekil 2. Solhan yöresinden bazı arılık alanlar

\section{MATERYAL VE METOT}

Çalışmanın materyalini, Solhan bölgesinde yapılan arazi çalışmaları, gözlemler ve arıcılara uygulanan anketler (Ek. 1) neticesinde toplanan arıların sıklıkla ziyaret ettiği bitkiler oluşturmaktadır. Arazi çalışmalarında toplanılan bitkiler herbaryum tekniklerine göre koleksiyon haline getirilmiş ve teşhisleri için Davis'in "Flora of Turkey and The East Aegean Islands" adlı kitapları kullanılmıştır [7]. Çalışmalar sonucunda tespit edilen arı bitkileri, ait oldukları familyaları baz alınarak alfabetik olarak sıralanmıştır (Tablo 1). Listede yer alan SP toplayıc1 kodu Solhan ve Pikom'u (Pilot Üniversite Koordinasyon Merkez Birimi) ifade eden kısaltmalardır. Toplanan bitkilerden alınan çiçek örnekleri palinolojik olarak değerlendirilmiş olup en s1k ziyaret edilen önemli bazı arı bitkilerinin 1ş1k mikroskobu ile çekilmiş polen mikro fotoğrafları kullanılarak polen atlası hazırlanmıştır (Şekil 3). Ayrıca çalışma kapsamında arıların sıklıkla ziyaret ettiği bitkiler ile ilgili arıcılara uygulanan anketlerin istatistiksel analizleri hesaplanmıştır 


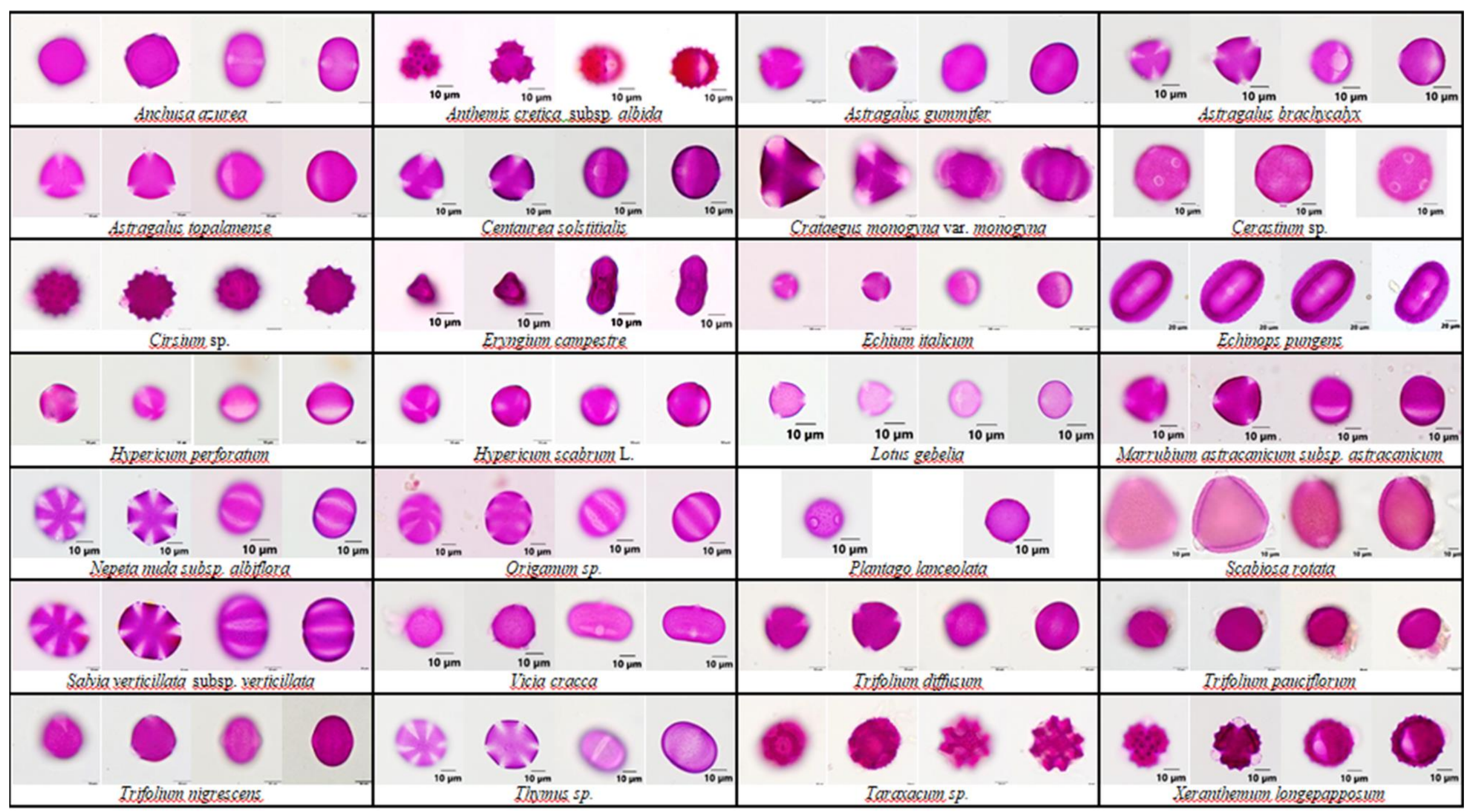

Sekil 3. Polen mikrofotoğrafları 


\section{BULGULAR}

Solhan ve çevresinde yapılan arazi gezileri sonucunda Hazarşah - Şerafettin dağları bölgesi, Yenibaşak - Kale çevresi, Tavz kuzey yamaçları - Gelintepe bölgesi, Mezra Şadon bölgesi, Beroj bölgesi, Arakonak bölgesi, Perğu/Asmakaya bölgesi yöredeki önemli arıcılık merkezleri olarak tespit edilmiştir. Araştırmalar sonucunda 25 familyaya ait 100 taksonun yörede arıcılık açısından önemli potansiyele sahip olduğu tespit edilmiştir (Tablo. 1). Solhan yöresinde ballı bitki taksonlarının genellikle Asteraceae, Lamiaceae, Fabaceae, Rosaceae, Caprifoliaceae, Caryophyllaceae ve Hypericaceae familyalarında yoğunlaştığı görülmektedir (Şekil 4).

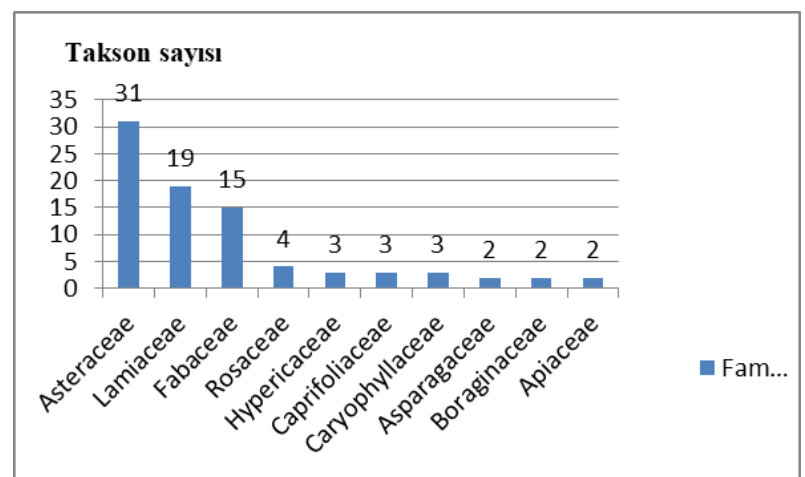

Şekil 4. En fazla taksona sahip familyalar

\section{SONUÇ}

Çalışmamız sonucunda kaydedilen 25 familyaya ait 100 bitki taksonundan 7' si endemik ve 4'ü de lokal endemik olarak kaydedilmiştir. Endemik taksonlar; Achillea schischkinii Sosn., Phlomis linearis Boiss. \& Balansa, Potentilla anatolica Peşmen'dir. Lokal endemik taksonlar ise Astragalus topalanense İlçim \& Behçet, Cirsium yildizianum Arabacı\& Dirmenci, Lathyrus satdaghensis P.H.Davis, Malabaila lasiocarpa Boiss.' dir (Tablo 1).

Arıların sıklıkla ziyaret ettiği bitkilerden en çok takson içeren ilk 5 familya sırasıyla şu şekildedir; Asteraceae (31), Lamiaceae (19), Fabaceae (15), Rosaceae (4), Caprifoliaceae (3), Caryophyllaceae (3) ve Hypericaceae (3). Çalışma sonuçları yakın bölgelerde yapılmış Behçet ve Yapar [9], Bakoğlu vd. [10] ve Öztürk ve Erkan [11] diğer araştırmalar ile karşılaştırıldığında ilk 5 familya bazında benzerlik göstermektedir (Tablo 2). Asteraceae, Lamiaceae ve Fabaceae bütün çalışmalarda ilk 5 familya arasında bulunmaktadır. Rosaceae familyası Bakoğlu vd. tarafından yapılan çalışmada ilk 5'te yer bulmazken diğer 3 çalışmada ilk 5 familya arasında bulunmaktadır. Solhan yöresinde yapılan yoğun alan gözlemleri ve anket çalışmaları Hypericaceae ve Caprifoliaceae familyalarının arıcılık açısından önemli olduğunu göstermektedir. Bu iki familya yakın ve çevre alanlarda yapılmış diğer araştırmalarda ilk 5 familya arasında yer almamaktadır.
Tablo 2. Yakın ve çevre alanlardaki araştırmalarla karşılaştırma

\begin{tabular}{|c|c|c|c|}
\hline Araştırma & $\begin{array}{l}\text { Çalışma } \\
\text { Alanı }\end{array}$ & $\begin{array}{l}\text { Tespit } \\
\text { edilen } \\
\text { takson } \\
\text { Sayısı } \\
\end{array}$ & İlk 5 familya \\
\hline $\begin{array}{l}\text { Solhan } \quad \text { Ar1 } \\
\text { Floras1 }\end{array}$ & $\begin{array}{l}\text { Solhan İlçesi } \\
\text { (Bingöl) }\end{array}$ & 100 & $\begin{array}{l}\text { Asteraceae } \\
\text { Lamiaceae } \\
\text { Fabaceae } \\
\text { Rosaceae } \\
\text { Caprifoliaceae } \\
\text { Hypericaceae }\end{array}$ \\
\hline $\begin{array}{l}\text { Behçet ve } \\
\text { Yapar (2019) }\end{array}$ & $\begin{array}{l}\text { Metan dağ1 } \\
\text { çevresi } \\
\text { (Bingöl) }\end{array}$ & 211 & $\begin{array}{l}\text { Asteraceae } \\
\text { Lamiaceae } \\
\text { Fabaceae } \\
\text { Rosaceae } \\
\text { Apiaceae } \\
\end{array}$ \\
\hline $\begin{array}{l}\text { Bakoğlu vd. } \\
(2013)\end{array}$ & Bingöl & 80 & $\begin{array}{l}\text { Asteraceae } \\
\text { Fabaceae } \\
\text { Apiaceae } \\
\text { Lamiaceae } \\
\text { Boraginaceae }\end{array}$ \\
\hline $\begin{array}{l}\text { Öztürk ve } \\
\text { Erkan (2010) }\end{array}$ & Van & 282 & $\begin{array}{l}\text { Fabaceae } \\
\text { Asteraceae } \\
\text { Lamiaceae } \\
\text { Rosaceae } \\
\text { Caryophyllaceae } \\
\end{array}$ \\
\hline
\end{tabular}

Arıcılar ile yapılan anket çalışmaları sonucunda arıların sıklıkla ziyaret ettiği bitkilerin atıf sayıları (anketlerde ilgili bitkiyi yazan kişi sayısı) ve yüzdelik olarak arı bitkisi olarak bilinme oranları Tablo 3' de gösterildiği şekilde hesaplanmıştır. Solhan bölgesindeki farklı alanlardan seçilen 15 arıcı ile yapılan anket sonuçlarına göre atıf sayısı en yüksek olan bitkiler 15 atıf olarak kekik taksonlar1 (Thymus kotschyanus, Thymus pubescens), geven taksonlar1 (Astragalus gummifer, Astragalus brachycalyx, üçgül/nefil taksonları (Trifolium diffusum, T. nigrescens, T. pauciflorum, Trifolium resupinatum) olarak belirlenmiştir. $\mathrm{Bu}$ taksonları ballıbaba olarak adlandırılan Marrubium astracanicum (12 atıf), Nepeta nuda (10 atıf), yörede tusi ismi ile bilinen Eryngium campestre (9 atıf), ve gezı ismi ile bilinen Xeranthemum longepapposum (9 atıf) olarak izlemektedir (Tablo 3). 
Tablo 3. Arıcılar ile yapılan anketlerin frekans ve yüzde değerleri

\begin{tabular}{|c|c|c|c|}
\hline $\begin{array}{c}\text { Arı bitkisi } \\
\text { (yöresel } \\
\text { isimler) }\end{array}$ & Bilimsel adı & $\begin{array}{c}\text { Kaynak } \\
\text { arıcı } \\
\text { sayısı }\end{array}$ & $\begin{array}{l}\text { Bilinme } \\
\text { yüzdesi } \\
(\%)\end{array}$ \\
\hline Geven, guni & $\begin{array}{l}\text { Astragalus gummifer } \\
\text { Astragalus brachycalyx }\end{array}$ & 15 & $\% 100$ \\
\hline Diken, Telı & Centaurea sp. & 4 & $\% 26$ \\
\hline Diken, Telı & Cirsium sp. & 5 & $\% 33$ \\
\hline Beyaz çiçek & Cerastium sp. & 4 & $\% 26$ \\
\hline $\begin{array}{l}\text { Tusi, Kinger } \\
\text { nevi }\end{array}$ & Eryngium campestre & 9 & $\% 60$ \\
\hline Kırkor, Çakşır & Ferulago sp. & 3 & $\% 20$ \\
\hline Kenger & Gundelia tournefortii & 6 & $\% 40$ \\
\hline Kantaron & Hypericum sp. & 8 & $\% 53$ \\
\hline Jehri & Lotus sp. & 7 & $\% 46$ \\
\hline Ballıbaba & Marrubium astracanicum & 12 & $\% 80$ \\
\hline Ballıbaba & Nepeta nuda & 10 & $\% 66$ \\
\hline $\begin{array}{l}\text { Kinger heron, } \\
\text { diken }\end{array}$ & Onopordum sp. & 3 & $\% 20$ \\
\hline $\begin{array}{l}\text { Meşe, Mazer, } \\
\text { Azgiler }\end{array}$ & Quercus petrae & 4 & $\% 26$ \\
\hline Söğüt, Valer & Salix sp. & 2 & $\% 13$ \\
\hline Ballıbaba & Salvia sp. & 5 & $\% 33$ \\
\hline Gez1 & Scabiosa sp. & 7 & $\% 46$ \\
\hline Kekik, Onık & Thymus spp. & 15 & $\% 100$ \\
\hline $\begin{array}{l}\text { Nefil, Üçgül, } \\
\text { Argud }\end{array}$ & Trifolium spp. & 15 & $\% 100$ \\
\hline Gez1 & $\begin{array}{l}\text { Xeranthemum longepapp } \\
\text { osum }\end{array}$ & 9 & $\% 60$ \\
\hline
\end{tabular}

Araştırma alanında tespit edilen bitkilerin büyük çoğunluğunun arılar tarafindan nektar ve polen kaynağı olarak kullanıldığı görülmektedir. Bununla beraber yörede gez adı verilen genellikle Mayıs - Haziran döneminde görülen ve nem oranının yüksek olduğu günlerde Quercus (meşe), Juglans regia L. (ceviz) vb. ağaç formlarının yapraklarında bir tür böcek etkisiyle oluştuğu düşünülen salg1 yörede bilinen bir durumdur (Şekil 5). Bu salgının arılar tarafından toplandığı ve özellikle meşe salgısının yoğun olduğu dönemlerde oldukça koyu renkli (siyaha yakın) bir tür salgı balı elde edildiği arıcılar arasında çokça bilinmektedir. Bu salgı oluşan meşe yapraklarının eski dönemlerde halk tarafindan çokça toplanıp kaynatıldıktan sonra meşe pekmezi yapıldığı bilgisi de çalışmada ayrıca kayıt edilmiştir.

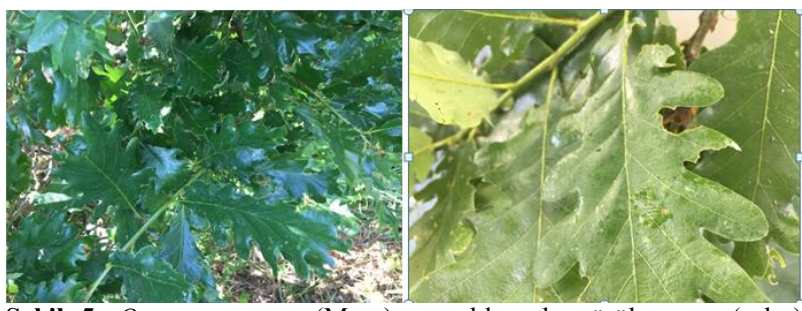

Şekil 5. Quercus petrae (Meşe) yapraklarında görülen gez (salgı) durumu

Solhan arı florası çeşitliliği bakımından zengin bir bölge olup, mevcut olan arıcılık uygulamaları için arı florası türlerinin korunması gerekmektedir. Çalışma alanında arıların ziyaret edip bal materyali aldıkları bitkiler yükseltilere (dağ etekleri, yaylalar) ve mevsimlere göre farklılıklar gösterebilmektedir. Araştırma alanında yapılan çalışmalar arıların ziyaret yoğunluğu ve arıcılarla yapılan görüşmeler göz önünde bulundurulduğunda yörede bazı taksonların arı bitkisi (ballı bitki) olarak daha çok ön plana çıktığ 1 görülmektedir. Çiçeklenme dönemleri uzun, çiçek yapıları arılara daha uygun ve yörede geniş yayılışa sahip olan taksonlar arılar tarafindan daha sik ziyaret edilen bitkilerdir; Anchusa azurea, Anthemis cretica L. subsp. albida, Astragalus gummifer, Astragalus brachycalyx, Centaurea solstitialis, Crataegus monogyna Jacq. var. monogyna, Cerastium sp., Cirsium sp., Eryngium campestre, Echium italicum, Echinops pungens, Hypericum perforatum, $H$. scabrum, Lotus corniculatus, Lotus gebelia, Marrubium astracanicum subsp. astracanicum, Nepeta nuda subsp. albiflora, Origanum sp., Plantago lanceolata, Scabiosa rotata, Salvia verticillata subsp. verticillata, S. multicaulis, Vicia cracca, Trifolium diffusum, T. pauciflorum, T. nigrescens, Thymus sp.,, Taraxacum sp., ve Xeranthemum longepapposum bu kapsamda yörede ön plana çıkan taksonlardır. (Şekil 6).
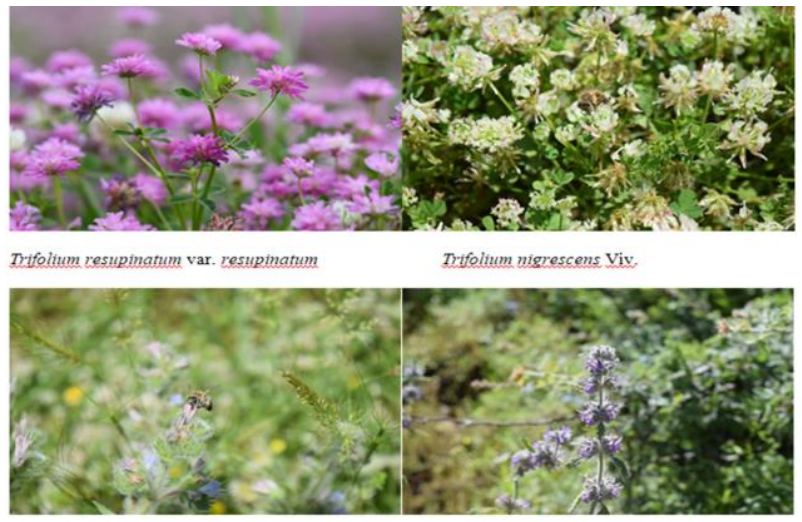

Echtum italicum L. Manrubrum astracanicum Jacg.

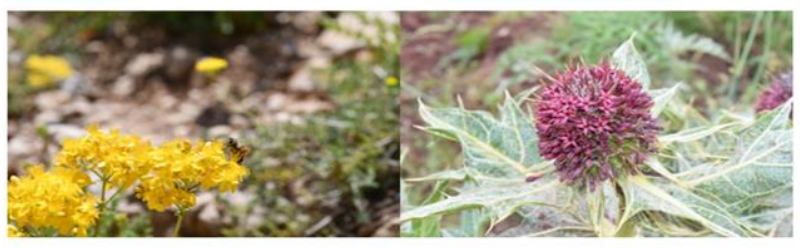

Hypericum scabrum L.

Gundelia tommefortii L. I

Şekil 6. Solhan yöresinden bazı önemli arı bitkileri 


\section{Teşekkür}

$\mathrm{Bu}$ çalışma Bingöl Üniversitesi Bölgesel Kalkınma Odaklı Misyon Farklılaşması ve İhtisaslaşması Programı (Tarım ve Havza Bazlı Kalkınma Alanında) tarafından (Proje no: PİKOM-Bitki.2018.002) desteklenmiştir

\section{KAYNAKLAR}

[1] Gökyiğit A N. Türkiye'nin Biyolojik Zenginliği ve Korunması. Ali Nihat Gökyiğit Vakfı Yayınları, 2013.

[2] Güner A. (ed.) Türkiye Bitkileri Listesi (Damarlı Bitkiler). Nezahat Gökyiğit Botanik Bahçesi Yayınları Flora Dizisi 1, İstanbul, 333-337, 2012.

[3] Sıralı Y D. Arıcılığın Türkiye İçin Önemi. Arıcılık Araştırma Dergisi Sayı 4; 3- 4, 2010.

[4] Doğaroğlu M. Genç F. Üretim kolonilerinin verimliliği ile ilgili bakım ve yönetim sorunları. Türkiye II. Teknik Arıcılık Kongresi, 101-107, Ankara, 1994.

[5] TUİK. Türkiye İstatistik Kurumu (TÜİK), 2020. (www.tuik.gov.tr)

[6] Sandal E K. Kan C. Bingöl İli'nde Arıcılık Faaliyetleri. Türk Coğrafya Dergisi, 60, 1-12, 2013.

[7] Davis, P H. Flora of Turkey Volume1- 9. Edinburg University Press, Edinburg, 1967.

[8] Davis, P H. Flora of Turkey. Volume 10. Edinburg University Press, Edinburg, 1988.

[9] Behçet L, Yapar Y. Matan Dağı (Bingöl) florasında arıcılık açısından önemli bitkiler, Biological Diversity and Conservation, 12/1, 149-159, 2019.

[10] Bakoğlu A, Kutlu M A, Kökten K. Bingöl yöresinde bal arısı (Apis mellifera L.) için önemli olan bitkilerin tespiti, ömür uzunlukları ve çiçeklenme tarihleri. Türkiye 10. Tarla bitkileri kongresi. DOI: 10.13140/RG.2.1.5027.8807. 2013.

[11] Öztürk F, Erkan C. Bee plants of Van lake basin (Turkey). International Journal of Botany, 6(2), 101- 106, 2010.

\section{Ekler}

Ek A. Ar1 florası belirme anketi

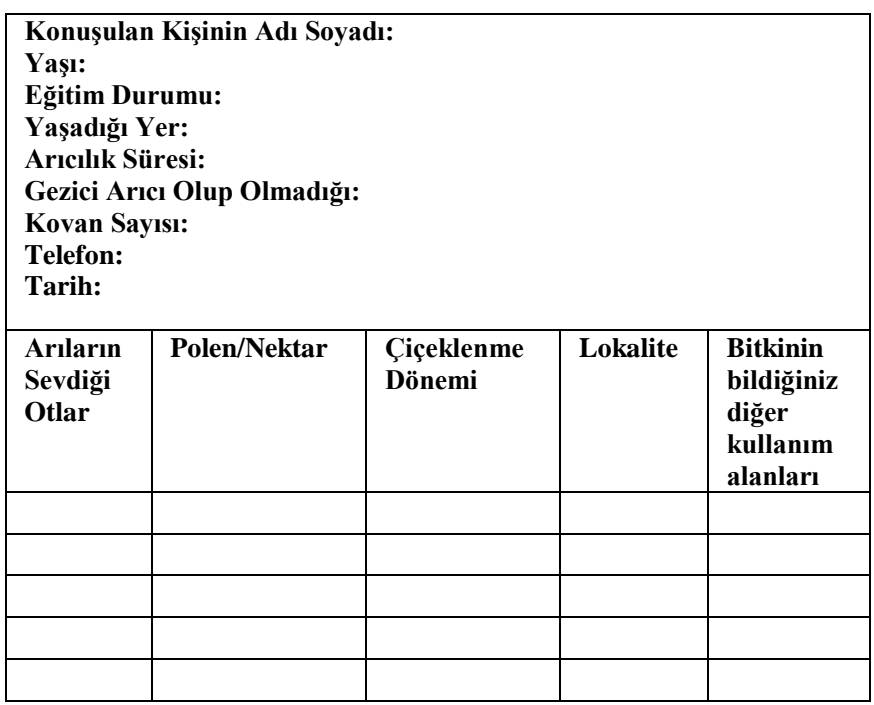


Tablo 1. Solhan Bölgesi'nde tespit edilen arı bitkileri listesi.

\begin{tabular}{|c|c|c|c|c|c|c|}
\hline \multicolumn{2}{|c|}{ Takson } & \multirow{2}{*}{$\begin{array}{l}\text { Familyası } \\
\text { Acanthaceae }\end{array}$} & \multirow[t]{2}{*}{ Yöresel İsimler } & \multirow{2}{*}{\begin{tabular}{|r|}
$\begin{array}{l}\text { Ciçeklenme } \\
\text { periyodu (Ay) }\end{array}$ \\
$6-7$ \\
\end{tabular}} & \multirow{2}{*}{\begin{tabular}{|l|} 
Arıcılık açısından önemi \\
Polen
\end{tabular}} & \multirow{2}{*}{$\begin{array}{l}\begin{array}{l}\text { Toplayıcı } \\
\text { numarası }\end{array} \\
\text { SP382 }\end{array}$} \\
\hline 1. & Acanthus dioscoridis $\mathrm{L}$. & & & & & \\
\hline 2. & Heracleum persicum Desf. & Apiaceae & Helerg & $6-7$ & Nektar/Polen & SP205 \\
\hline 3. & Eryngium campestre $\mathrm{L}$. & Apiaceae & Tusi, Kinger nevi & $5-7$ & Nektar/Polen & SP340 \\
\hline 4. & Malabaila lasiocarpa Boiss. ${ }^{*}$ & Asparagaceae & & 6-8 & Polen & SP68 \\
\hline 5. & Ornithogalum narbonense $\mathrm{L}$. & Asparagaceae & Zulk & $4-6$ & Nektar/Polen & SP229 \\
\hline 6. & Achillea millefolium $\mathrm{L}$. subsp. millefolium & Asteraceae & Zerrk & $6-9$ & Nektar/Polen & SP136 \\
\hline 7. & A. schischkinii Sosn. ${ }^{*}$ & Asteraceae & Zerık & $5-7$ & Nektar/Polen & SP184 \\
\hline 8. & A. tenuifolia Lam. & Asteraceae & Zerik & $5-8$ & Nektar/Polen & SP27 \\
\hline 9. & A. vermicularis Trin. & Asteraceae & Zerik & $6-9$ & Nektar/Polen & SP200 \\
\hline 10. & Anthemis cretica L. subsp. albida (Boiss.) Grierson & Asteraceae & Papatya & $5-7$ & Nektar/Polen & SP58 \\
\hline 11. & Bellis perennis $\mathrm{L}$. & Asteraceae & Papatya & 3-8 & Polen & SP02 \\
\hline 12. & Carduus nutans L. subsp. nutans & Asteraceae & Eşek dikeni & $5-8$ & Nektar/Polen & SP135 \\
\hline 13. & Centaurea iberica Trev. ex Sprengel & Asteraceae & Telı & $7-8$ & Nektar/Polen & SP380 \\
\hline 14. & Centaurea saligna $(\mathrm{K} . \mathrm{Koch})$ Wagenitz* & Asteraceae & Talık & $7-8$ & Nektar/Polen & SP381 \\
\hline 15. & Centaurea solstitialis L. subsp. solstitialis & Asteraceae & Telı & $6-8$ & Nektar/Polen & SP258 \\
\hline 16. & C. spectabilis (DC.) Sch. Bip. var. spectabilis & Asteraceae & & 6-7 & Nektar/Polen & SP107 \\
\hline 17. & C. spectabilis (DC.) Sch. Bip. var. microlopha (Boiss.) Wagenitz & Asteraceae & & 6-7 & Nektar/Polen & SP212 \\
\hline 18. & C. virgata Lam. & Asteraceae & & 6-7 & Nektar/Polen & SP266 \\
\hline 19. & Cichorium sp. & Asteraceae & & 6-7 & Nektar/Polen & SP376 \\
\hline 20. & Cirsium arvense (L.) Scop & Asteraceae & Kinger & $6-7$ & Nektar/Polen & SP48 \\
\hline 21. & Cirsium yildizianum Arabacı\& Dirmenci ${ }^{\times}$ & Asteraceae & Kinger heron & $7-8$ & Nektar/Polen & SP351 \\
\hline 22. & Cota altissima (L.) J.Gay & Asteraceae & & 6-7 & Nektar/Polen & SP34 \\
\hline 23. & Crepis sancta (L.) Bornm.subsp. obovata (Boiss. \&Noë) Babc. & Asteraceae & & $6-7$ & Nektar/Polen & SP44 \\
\hline 24. & $\begin{array}{l}\text { Cyanus triumfettii (All.) Dostál ex Á. Löve \& D. Löve subsp. } \\
\text { triumfettii }\end{array}$ & Asteraceae & & $6-7$ & Nektar/Polen & SP24 \\
\hline 25. & Echinops pungens Trautv. var. pungens & Asteraceae & Herguet & 6-8 & Nektar/Polen & SP379 \\
\hline 26. & Echinops sp. & Asteraceae & Herguet & 6-7 & Nektar & SP344 \\
\hline 27. & Gundelia tournefortii L. var. tournefortii & Asteraceae & Kinger & 6-7 & Nektar & SP77 \\
\hline 28. & $\begin{array}{l}\text { Helichrysum arenarium (L.) Moench. subsp. rubicundum (K.Koch) } \\
\text { P.H.Davis \& Kupicha }\end{array}$ & Asteraceae & Sesum & $6-7$ & Nektar & SP194 \\
\hline 29. & H. plicatum DC. subsp. polyphyllum (Ledeb.) P.H.Davis \& Kupicka & Asteraceae & & 6-7 & Nektar & SP241 \\
\hline 30. & $\begin{array}{l}\text { H. plicatum DC. subsp. pseudoplicatum (Nábělek) P.H. Davis \& } \\
\text { Kupicka }\end{array}$ & Asteraceae & & 6-7 & Nektar & SP280 \\
\hline 31. & Leontodon asperrimus (Willd.) Endl. & Asteraceae & & 6-7 & Nektar/Polen & SP183 \\
\hline
\end{tabular}




\begin{tabular}{|c|c|c|c|c|c|c|}
\hline 32. & Onopordum acanthium $\mathrm{L}$. & Asteraceae & Kinger heron & $6-7$ & Nektar/Polen & SP346 \\
\hline 33. & Onopordum candidum Nábělek & Asteraceae & Kinger & 6-7 & Nektar/Polen & SP272 \\
\hline 34. & Taraxacum fedtschenkoi Hand.-Mazz & Asteraceae & & $5-6$ & Polen & SP264 \\
\hline 35. & Tussilago farfara $\mathrm{L}$. & Asteraceae & & $5-6$ & Nektar/Polen & SP1 \\
\hline 36. & Xeranthemum longepapposum Fisch. \& C.A.Mey. & Asteraceae & Gez1 & 6-8 & Nektar/Polen & SP370 \\
\hline 37. & Anchusa azurea Mill. var. azurea & Boraginaceae & Gelzun & $5-7$ & Nektar/Polen & SP20 \\
\hline 38. & Echium italicum $\mathrm{L}$. & Boraginaceae & Arı otu & 6-7 & Nektar/Polen & SP53 \\
\hline 39. & Aethionema grandiflorum Boiss. \& Hohen. & Brassicaceae & & 6-7 & Polen & SP126 \\
\hline 40. & Campanula involucrata Aucherex A.DC. & Campanulaceae & & 6-7 & Nektar/Polen & SP79 \\
\hline 41. & Scabiosa calocephala Boiss & Caprifoliaceae & $\begin{array}{l}\text { Gezı } \\
\text { Süpürge otu }\end{array}$ & 6-7 & Nektar/Polen & SP42 \\
\hline 42. & S. columbaria L. subsp. columbaria var. columbaria & Caprifoliaceae & $\begin{array}{l}\text { Gezı } \\
\text { Süpürge otu }\end{array}$ & 6-7 & Nektar/Polen & SP120 \\
\hline 43. & S. rotata M. Bieb. & Caprifoliaceae & $\begin{array}{l}\text { Gezı } \\
\text { Süpürge otu }\end{array}$ & 6-7 & Nektar/Polen & SP50 \\
\hline 44. & Cerastium sp. & Caryophyllaceae & & $6-7$ & Nektar/Polen & SP372 \\
\hline 45. & Silene compacta Fisch. ex Hornem. & Caryophyllaceae & Dolma hatun & $5-7$ & Polen & SP128 \\
\hline 46. & S. spergulifolia (Desf.) M.Bieb. & Caryophyllaceae & & $5-7$ & Polen & SP39 \\
\hline 47. & Convolvulus lineatus $\mathrm{L}$. & Convolvulaceae & & 6-7 & Nektar/Polen & SP118 \\
\hline 48. & Sedum sp. & Crassulaceae & & $6-7$ & Polen & SP350 \\
\hline 49. & Euphorbia esula L. subsp. tommasiniana (Bertol.) Kuzmanov & Euphorbiaceae & & 6-7 & Nektar/Polen & SP70 \\
\hline 5 50. & Astragalus brachycalyx Fisch. ex Boiss. & Fabaceae & $\begin{array}{l}\text { Heşgun, tırgu, Ac1 } \\
\text { geven }\end{array}$ & $7-8$ & Nektar/Polen & SP378 \\
\hline 51. & Astragalus gummifer Labill. & Fabaceae & Geven, Guni & $6-7$ & Nektar/Polen & SP275 \\
\hline 52. & Astragalus onobrychis $\mathrm{L}$. & Fabaceae & Geven & $6-7$ & Nektar/Polen & SP129 \\
\hline 53. & Astragalus topalanense İlçim \& Behçet * & Fabaceae & Geven & $6-7$ & Nektar & SP18 \\
\hline 54. & Astragalus caspicus M.Bieb. & Fabaceae & Geven & $6-7$ & Nektar & SP368 \\
\hline 55. & Lathyrus satdaghensis P.H.Davis* & Fabaceae & Karvil & $6-7$ & Nektar/Polen & SP398 \\
\hline 56. & Lotus corniculatus $\mathrm{L}$. & Fabaceae & Jehri,, Karvil & $5-7$ & Nektar/Polen & SP343 \\
\hline 57. & Lotus gebelia Vent. var. gebelia & Fabaceae & $\begin{array}{l}\text { Jehri, } \\
\text { Karvil }\end{array}$ & $5-7$ & Nektar/Polen & SP111 \\
\hline 58. & Medicago lupulina $\mathrm{L}$. & Fabaceae & & $5-6$ & Nektar/Polen & SP105 \\
\hline 59. & Securigera orientalis (Mill.) Lassen subsp. orientalis & Fabaceae & & $5-6$ & Nektar & SP25 \\
\hline 60. & Trifolium diffusum Ehrh. & Fabaceae & $\begin{array}{l}\text { Nefil, Üçgül } \\
\text { Argud }\end{array}$ & $5-6$ & Nektar/Polen & SP86 \\
\hline 61. & T. nigrescens Viv. subsp. nigrescens & Fabaceae & $\begin{array}{l}\text { Nefil, Üçgül } \\
\text { Argud }\end{array}$ & $5-6$ & Nektar/Polen & SP85 \\
\hline
\end{tabular}




\begin{tabular}{|c|c|c|c|c|c|c|}
\hline 62. & T. pauciflorum d'Urv. & Fabaceae & $\begin{array}{l}\text { Nefil, Üçgül } \\
\text { Argud }\end{array}$ & $5-6$ & Nektar/Polen & SP36 \\
\hline 63. & T. resupinatum $\mathrm{L}$. & Fabaceae & $\begin{array}{l}\text { Nefil, Üçgül } \\
\text { Argud }\end{array}$ & $5-6$ & Nektar/Polen & SP369 \\
\hline 64. & Vicia cracca $\mathrm{L}$. & Fabaceae & $\begin{array}{ll}\text { Mercur, } \\
\text { Kewlu }\end{array}$ Holoz, & $5-6$ & Nektar/Polen & SP349 \\
\hline 65. & Quercus petraea (Matt.) Liebl. & Fagaceae & Meşe, Mazer & $6-7$ & Salg1 & SP375 \\
\hline 66. & Hypericum lydium Boiss. & Hypericaceae & Kantaron & $5-7$ & Nektar/Polen & SP63 \\
\hline 67. & H. scabrum $\mathrm{L}$. & Hypericaceae & Kantaron & $5-7$ & Nektar/Polen & SP339 \\
\hline 68. & H. perforatum $\mathrm{L}$. & Hypericaceae & Kantaron & $5-8$ & Nektar/Polen & SP64 \\
\hline 69. & Lamium macrodon Boiss. \& Huet & Lamiaceae & & $4-6$ & Nektar/Polen & SP5 \\
\hline 70. & Marrubium astracanicum Jacq. subsp. astracanicum & Lamiaceae & Ballıbaba & $5-9$ & Nektar/Polen & SP110 \\
\hline 71. & Mentha longifolia (L.) L. subsp. longifolia & Lamiaceae & $\begin{array}{l}\text { Pune } \\
\text { Nane }\end{array}$ & 6-8 & Nektar/Polen & SP206 \\
\hline 72. & Nepeta nuda L. subsp. albiflora (Boiss.) Gams & Lamiaceae & Ballıbaba & $6-8$ & Polen & SP195 \\
\hline 73. & Origanum vulgare L. subsp. gracile (K.Koch) Iestw. & Lamiaceae & $\begin{array}{l}\text { Onık } \\
\text { Kekik }\end{array}$ & $6-10$ & Nektar/Polen & SP208 \\
\hline 74. & Phlomis linearis Boiss. \& Balansa * & Lamiaceae & & $5-8$ & Polen & SP230 \\
\hline 75. & Phlomis pungens Willd. & Lamiaceae & & $6-7$ & Nektar/Polen & SP374 \\
\hline 76. & Phlomis rigida Labill. & Lamiaceae & & $6-7$ & Polen & SP377 \\
\hline 77. & Prunella vulgaris $\mathrm{L}$. & Lamiaceae & & $5-9$ & Polen & SP202 \\
\hline 78. & Salvia frigida Boiss. & Lamiaceae & & $5-7$ & Nektar/Polen & SP67 \\
\hline 79. & Salvia multicaulis Vahl & Lamiaceae & & $4-7$ & Nektar/Polen & SP73 \\
\hline 80. & Salvia verticillata $\mathrm{L}$. subsp. verticillata & Lamiaceae & & $6-8$ & Nektar/Polen & SP253 \\
\hline 81. & Salvia virgata Jacq. & Lamiaceae & & $7-8$ & Nektar/Polen & SP383 \\
\hline 82. & Satureja hortensis L. & Lamiaceae & & $6-9$ & Nektar/Polen & SP257 \\
\hline 83. & Stachys аппиа (L) L. subsp. аппиа var. аппиа & Lamiaceae & & $4-9$ & Nektar/Polen & SP182 \\
\hline 84. & Stachys lavandulifolia Vahl var. lavandulifolia & Lamiaceae & $\begin{array}{l}\text { Çaye que } \\
\text { Dağ çayı }\end{array}$ & $5-8$ & Nektar/Polen & SP51 \\
\hline 85. & Teucrium orientale L. var. puberulens Ekim & Lamiaceae & & $6-9$ & Nektar/Polen & SP276 \\
\hline 86. & Thymus kotschyanus Boiss. \& Hohen. & Lamiaceae & $\begin{array}{l}\text { Onık } \\
\text { Kekik }\end{array}$ & $6-8$ & Nektar/Polen & SP373 \\
\hline 87. & T. pubescens Boiss. \& Kotschy ex Celak & Lamiaceae & $\begin{array}{l}\text { Onık } \\
\text { Kekik }\end{array}$ & $6-8$ & Nektar/Polen & SP186 \\
\hline 88. & Alcea apterocarpa Boiss. & Malvaceae & Hatmi, Hiri & $5-8$ & Nektar/Polen & SP52 \\
\hline 89. & Papaver dubium L. subsp. dubium & Papaveraceae & & $4-6$ & Polen & SP56 \\
\hline 90. & Plantago lanceolata $\mathrm{L}$. & Plantaginaceae & $\begin{array}{l}\text { Pel heves } \\
\text { Sinir otu }\end{array}$ & $4-9$ & Polen & SP104 \\
\hline 91. & Acantholimon calvertii Boiss. var. calvertii & Plumbaginaceae & Ging1l, Prongol & $6-7$ & Nektar & SP177 \\
\hline 92. & Acantholimon armenum Boiss. \& Huet. & Plumbaginaceae & Gingll & $7-8$ & Nektar & SP384 \\
\hline 93. & Rumex acetocella $\mathrm{L}$. & Polygonaceae & Tirşık & $4-6$ & Polen & SP174 \\
\hline
\end{tabular}




\begin{tabular}{|c|c|c|c|c|c|c|}
\hline 94. & Ranunculus kochii Ledeb. & Ranunculaceae & & $4-7$ & Polen & SP15 \\
\hline 95. & Crataegus monogyna Jacq. var. monogyna & Rosaceae & $\begin{array}{l}\text { Sinz } \\
\text { Sez } \\
\end{array}$ & $4-6$ & Nektar/Polen & SP33 \\
\hline 96. & Potentilla anatolica Peşmen ${ }^{*}$ & Rosaceae & & $5-8$ & Nektar/Polen & SP271 \\
\hline 97. & Prunus divaricata Ledeb. var. divaricata & Rosaceae & Alıç & $4-5$ & Nektar/Polen & SP222 \\
\hline 98. & Rosa canina $\mathrm{L}$. & Rosaceae & $\begin{array}{l}\text { Surgul } \\
\text { Kuşburnu }\end{array}$ & $5-7$ & Nektar/Polen & SP223 \\
\hline 99. & Salix spp. & $\underline{\text { Salicaceae }}$ & Valer & $5-6$ & Nektar/Polen/Propolis & SP371 \\
\hline 100. & Urtica spp. & Urticaceae & $\begin{array}{l}\text { Gezgezık } \\
\text { Deriznek }\end{array}$ & $6-7$ & Nektar/Polen & SP342 \\
\hline
\end{tabular}

